Honan within the last three or four years, and, in a less severe form, in one or two of the adjoining provinces. Shansi is still suffering. And now the south-east of the province of Kansah has been visited by a destructive earthquake. The Peking Gazette of the 22nd of August states that a memorial has been received from Tso Tsung-t'ang, Governor-General of Shensi and Kansuh, reporting that on June 29 a slight trembling was felt at Chieh Chow, and at other sub-prefectures and districts within the province of Kansuh. This trembling, which occurred at first on alternate days and afterwards continued for several successive days, did not entirely cease until July II. The earthquake would appear to have reached its height on the third day; for Governor-General Tso reports that on July I there was a violent shaking accompanied by a noise. A temple, several official residences, and many dwelling-houses were completely destroyed, and many persons were killed and injured.

In the Imperial edict Tso Tsung-t'ang is directed to send officers to the scene of the calamity to hold an investigation into the matter and afford relief to the sufferers.

Canton, September $\mathbf{3}$

\section{Vertical Shafts in the Chalk in Kent}

IN the current number of Good Words there is a pleasant, gossiping paper by the Rev. J. G. Wood, giving an account of the curious well-like shafts found in the chalk about Erith. They are 40 feet to Ioo feet in depth. Mr. Wood states that the sides show traces of having been wrought with picks made of deer antlers. $\mathrm{He}$ appears to accept the theory of local archæologists that the shafts were executed in "prehistoric" times, in the quest for flints for weapons or for some less obvious purpose.

Under any circumstances $I$ should be loth to dispute the view of so competent an authority, and in this instance I have no local knowledge to guide me; but I should be grateful if some of your readers would satisfy me on the following point:-Is there any instance of similar excavations which have been conclusively proved to be the work of savages ancient or modern? I know of none within my own personal experience.

Burrows on the "adit" or "gallery" principle, i.e., more or less horizontal, can be carried surprisingly far, so long as the roof does not fall in. We see this in the abodes of certain quadrupeds. But, to carry down a vertical shaft a few feet in diameter to a depth of 40 feet to roo feet from the surface, even in a soil as favourable as chalk, appears to me to involve recourse to mechanical appliances not yet observed in use among primitive races. If I am wrong in this matter, the mode of excavation pursued by these rude shaft-sinkers certainly affords interesting matter for study.

London, November I

H. M. C.

\section{THE FUNCTIONS OF UNIVERSITIES}

W'E reproduce with pleasure the following extract from an article on this subject from the Times of Friday last, in connection with Prof. Max Müller's address at the Birmingham Midland Institute:-

It would doubtless be unjust, as Prof. Müller points out in his address, to attribute the lack of spontaneity, the tendency to mechanical uniformity in academical studies, exclusively to the influence of an elaborate system of examinations. Examinations are clearly necessary, as he justly contends, even though they are no better than a necessary evil; but they are rather means than ends, and they clearly become mischievous when they corrode and destroy the true spirit of academical life. Prof. Müller, a German professor in an English university, whose opiuion is on that account entitled to peculiar weight, draws a favourable contrast between English and foreign universities; the former, he says, are free and self-governed, and that gives them an unrivalled position in spite of all their faults. The remark is true and appropriate, especially as a rejoinder to the hasty and ill-considered criticisms of Prof. Helmholtz in his rectorial address at Berlin, delivered some time ago. But the corporate freedom of the English universities, is, unhappily, not inconsistent with a good deal of personal bondage. Let us contrast, for instance, the career of a graduate of a German university with that of an English Fellow of a college. The former, as soon as he has passed the necessary examinations for his degree, is perfectly free to follow his own bent. Even in taking his degree he is entitled to claim it, partly at least, on the ground of some dissertation which he has written containing the results of his own independent study and research. If he elects to follow an academical career, he becomes at first a Frivat-docent, and has to attract pupils, not by his power of preparing them for a particular examination, but by his command of all the available knowledge in a special branch of study, and by his capacity for enlarging its bounds. If he is called to be a professor, it is because he is known to be master of his subject, and to be keeping himself on a level with the march of knowledge in relation to it. The English graduade may have all the aspiration to follow this career of true academical freedom; but his pupils for the most part have no higher object than to pass an examination, and it is his business to prepare them for it. Any knowledge that he posseses beyond the range required for that purpose becomes a useless burden to him. The results of fresh research necessarily find their way but slowly into examination papers, and consequently the teacher at an English university, if he studies at all, is bound to study, not for himself, but for his pupils. He must learn all that they want to know, and he must put his knowledge into the form which will be most readily available for their purposes. Hence, if he has time to write at all, he writes summaries of history, essays in philosophy, or prepares a handy edition of a portion of a classic commonly read in the schools. A learned and scholarly edition of an author unrecognised in our somewhat narrow classical curriculum, a history like Grote's or Gibbon's, a philosophical work like the "Essay on the Human Understanding," or the "Critique of Pure Reason," are works hardly now to be looked for from a resident English graduate. Professorial work, of course, is different ; it is beginning now to be recognised that it is the business of a professor to study widely and deeply and to advance the bounds of knowledge. But if the coming generation of teachers, the professoriate of the future, is to be confined to the range of a rigid and cramping system of examinations, narrow in their content, but allembracing in their extent, what hope is there for that academic freedom, for that bracing spirit of living knowledge, of active thought, of ever-advancing study which, as Prof. Muiller tells us, it is the true function of a university to foster and keep alive?

The truth is, perhaps, that our universities are a little too careful of the functions they so admirably discharge of finishing schools, a little too unmindful of those higher duties to which Prof. Müller's address forcibly calls attention. All that they do is done well, but there is still one thing needful. "That is the true academic stage in every man's life when he learns to work, not to please others, be they schoolmasters or examiners, but to please himself; when he works for sheer love of work in and for the highest of all purposes-conquest of truth." How many of our English University students ever reach this stage at all? That they learn much and learn it well cannot be doubted, that they are examined much and are examined well is equally indisputable. But we should be very sorry to see the Universities complacently resign the function of making scholars in favour of that of testing the attainments of schoolboys. We are very far from arguing that examinations can be dispensed with altogether. They have their purpose, and it is a very necessary purpose to fulfil. It is their indirect results in stereotyping academical effort, in extinguishing academical freedom, in discouraging wide study, in checking individuality, and in repressing spontaneity, rather than their direct results, that we have to fear The evil is no 
slight one, and we fear it is still on the increase. "Unless," said Mill, "individuality shall be able to assert itself against the yoke of public opinion, Europe, notwithstanding its noble antecedents and its professed Christianity, will tend to become another China." Prof. Müller would persuade us that our Universities are a safeguard against this catastrophe. But when China is mentioned in connection with education, examinations are suggested by an irresistible association. If, therefore, England is to escape the fate of China, it is not only encouraging to reflect that the most conspicuous modern building in Prof. Müller's own University is the new Examination Schools.

DESCRIPTION OF AN INSTRUMENT FOR EXPLORING DARK CAVITIES WHICH ARE INACCESSIBLE TO DIRECT LIGHT

$\triangle \mathrm{N}$ electric lamp has recently been proposed for $\mathrm{A}^{\mathrm{N}}$ surgical and dental operations. ${ }^{x}$ Some years ago I designed an instrument for illuminating the dark cavities of the body which would, I think, be very serviceable in connection with an electric lamp.

This instrument consists of a series of prisms arranged somewhat as in the corona employed for spectrum analysis. The accompanying woodcut will be sufficiently intelligible

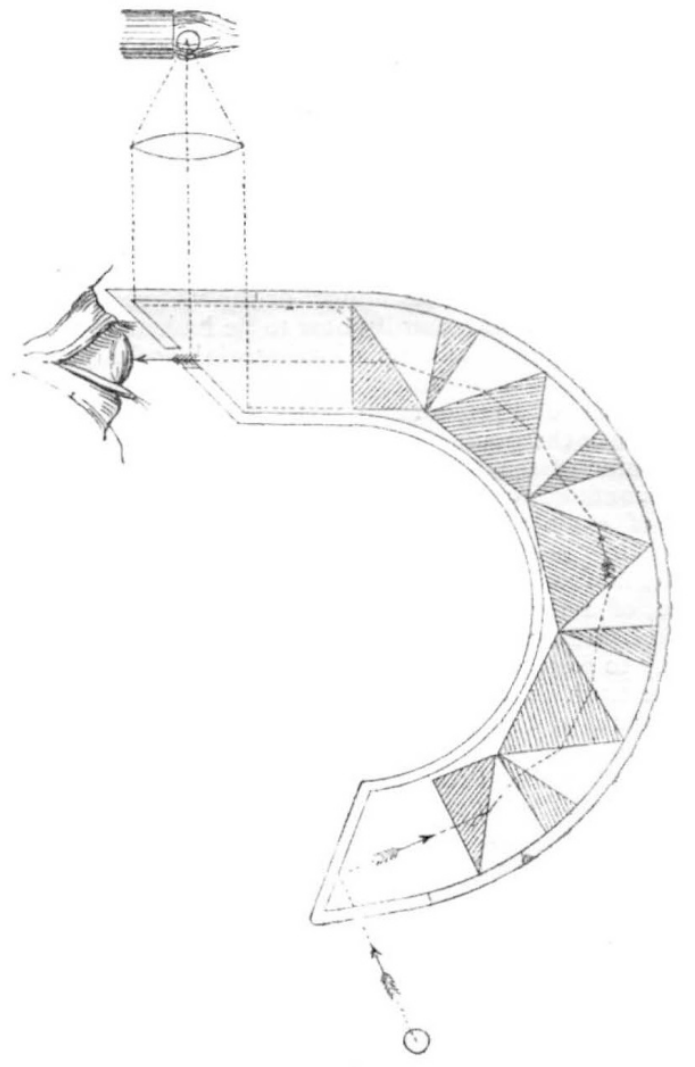

without any detailed description. The different prisms are of glass of such refractive indices as to secure achromatism, and the rays of light are bent round corners, so as, finally, to reach an external observer.

In most cases one or two such prisms will be sufficient, but any number may be employed so long as the loss of light from absorption, superficial reflection, and other causes is not so great as to defeat the object in view by destroying the distinctness of the image.

THOMAS STEVENSON

\section{IMPROVEMENTS IN BLEACHING}

A METHOD of applying the ordinary bleaching agents A (hypochlorites) in a new way has been invented by Count Dienheim de Brochocki of Paris. Instead of immersing the goods to be bleached in an ordinary "chloride of lime" vat, and subsequently souring, the inventor treats bleaching-powder with an acid and simultaneously passes air through the mixture, so that chlorine and hypochlorous acid vapours are mechanically carried off; the resulting gases are passed through an alkaline solution in such proportions as to saturate part or the whole of the alkali, or to supersaturate it at will. The resulting liquid is said to be sufficiently stable to be kept without change for two or three months; it can readily be prepared of a density of $30^{\circ}$ Beaumé, and acts as a bleacher without requiring any acidulation, and for many purposes is said to be superior to the ordinary bleaching-vat.

To this liquid the fanciful name "chlorozone" has been given, the inventor asserting that the oxidising power of a given quantity of bleaching-powder is increased by this treatment through the fixation in the product of some of the oxygen of the air used as carrying agent; the which oxygen he conceives to be liberated in the form of ozone in contact with the goods to be bleached! Although no experimental proof of the truth of this somewhat novel proposition appears to have been vouchsafed to the scientific world, yet it would seem that the new product has at least some practical advantages over the older bleaching agents, as it is used to a considerable extent in Paris, whilst works for its manufacture on a large scale have been recently erected at Warrington by Messrs. Nath. Holmes and Partners.

\section{HERING'S THEORY OF THE VISION OF LIGHT AND COLOURS ${ }^{1}$}

\section{III.}

I $\mathrm{N}$ the sixth and last memoir the author develops the part of his theory which has probably excited the most interest, namely, that of the vision of colours. He devotes his first section to the mode of classification of colours, and as this is not only the most important part, but differs materially from the generally received views, it is desirable to give its substance pretty fully.

He explains that, as he has based his general theory on what are naturally and physiologically two simple sensations, white and black, so he proposes to base his treatment of colours on the "natural system of coloursensations." He then has to seek what the simple natural sensations of colour are, neglecting in this classification all consideration of the physical properties usually connected with them. He inquires, therefore, what simple colour-sensations there are. Taking the six usually admitted, violet, blue, green, yellow, orange, and red, ho finds that two, namely, violet and orange, are obviously compound sensations; for in violet of every hue there can be distinguished clearly a mixture of the two sensations, blue and red; and similarly in orange there can always be traced the elements of red and yellow. The other four colours are red, ${ }^{2}$ green, blue, and yellow. None of the sensations known by these names contain, when pure, any semblance of another colour-sensation. These four, therefore, may with perfect correctness, as was pointed out by Leonardo da Vinci, be considered as simple or fundamental colour-sensations. On this account they have received special names, not borrowed from any coloured natural objects.

All other colour-sensations than these may be called mixed or compound sensations, as two elements can always be discovered in them; but it is a fixed principle

Continued from vol. xx. p. 639 .

2 'This, however, is not the spectral red, which contains a mixture of yellow. 